\title{
WHY ARE INCREMENTS SUCH ELUSIVE OBJECTS? AN AFTERTHOUGHT
}

\author{
Peter Auer
}

\begin{abstract}
It is argued that the type of unit expansions called 'increments' by Schegloff 1996 is too narrowly focused on English. While the structure of English makes it particularly suited for this kind of expansion, a typologically more satisfactory approach to unit expansion runs into problems if it remains on the syntactic plane alone. A full typology will have to take into account, not only prosody and semantics, but also action structure and pragmatics at large.
\end{abstract}

Keywords: Increment; TCU; unit expansion.

The term 'increment' is difficult to define and has been used quite differently by various authors over the last years. In my own 'increment' to this issue of PRAGMATICS, I will speculate on some of the reasons for this, and suggest an analysis of expansions of conversational units which is less taxonomic and more dynamic and does more justice to the emergence of turns and turn units as a multi-modal, multi-layered process. The basic argument is that increments as they are discussed now are just one very restricted way in which conversational units can be expanded, and that a more comprehensive and systematic approach to these expansions is necessary, not in the least in order to overcome the English language bias in the present discussion.

Schegloff (1996: 59), to whom the present discussion of 'increments' goes back, makes a basic distinction between the continuation of a TCU (which he calls an increment) and the continuation of a turn through the production of another TCU. In other parts of his 1996 paper he suggests that there may be turn components which are neither new TCUs nor increments, such as post-TCU repairs, tag questions, "postcompletion stance markers", and address and courtesy terms (1996: 90). There is, then, a multitude of things that can be part of a turn, and not all of these units are turnconstructional units. This contradicts 'technical' definitions of the TCU as a stretch of talk from one possible turn completion point to another, as they are sometimes found in the literature. A stretch of talk after a possible turn completion point and leading to another possible turn completion point, i.e.

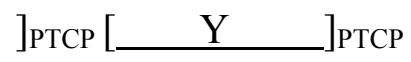


is not necessarily a TCU (it can, for instance, be an increment). Neither, incidentally, is a TCU necessarily a stretch of talk which can make up a turn in Schegloff's view, i.e.

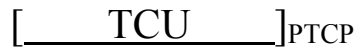

since there are also TCUs which project other TCUs (and therefore cannot occasion turn transition) (1996: 61).

If we accept that turns cannot be exhaustively 'parsed' into TCUs and that TCUs are just a certain class of objects that can occur within turns, we need criteria for recognising them and distinguishing them from increments, post-completion repairs, stance markers, etc.

Schegloff himself is interested in increments mainly from a syntactic point of view. He calls them "grammatically structured extensions" (1996: 90), and says that "some of these" (not all?) "add a new grammatical unit" to their host (ibid.). What is meant by "adding" or "grammatically structured" is not specified, but his examples suggest that increments must be fitted into the grammatical structure as it has developed so far without being projected by it. Address and courtesy terms seem to be excluded on the grounds that they have no grammatical relationship to the preceding TCU. Repairs and tag questions often do stand in a grammatical relationship to the preceding TCU, and since they are not counted as increments either, the latter seem to be required to be linearly related to the preceding TCU. Despite this syntactic approach (underspecified as it may be from a linguistic point of view), Schegloff needs an additional pragmatic criterion to distinguish increments from certain types of syntactic continuations of a sentence which clearly have different functions in conversation. In particular, they can perform a new action such as prompting or requesting a clarification (1996: 76) within a turn, or even in the following turn by another participant. This implies ex negativo, that for Schegloff, increments do not constitute an action of their own. Finally, although Schegloff does not discuss prosody as a defining feature of increments, his examples make it clear that a prosodic boundary between the host and its increment is necessary. Given his view of increments as linearly added syntactic units, this restriction is necessary since incremented sentences could not otherwise be distinguished from 'normal', nonincremented ones. E.g., in his example (p 91)

\section{I didn't know what days you had. classes or anything}

the omission of the prosodic boundary after the finite verb in the embedded clause would lead to a transitive sentence with classes or anything as the object phrase, without any clues to a syntactic expansion. (Note, incidentally, that the increment in this case is not, strictly speaking, a linear continuation of the syntactic construction produced so far, as Schegloff points out himself, without drawing any conclusions from it. While in the non-incremented structure, what days is the object phrase for the verb have, the increment turns this phrase retrospectively into an adverbial phrase and classes or anything into the object noun phrase. In this sense, the increment reorganises the preceding syntactic structure in a substantial way. Syntactically, it does not do the same job as a simple continuation such as in Schegloff's example of a clausal continuation, i.e. (p 90)

I'll give you a call tomorrow. When I get home. ) 
A different notion of 'increments' is proposed by Ford, Fox and Thompson (2002), who define increments as "nonmain-clause continuation after a possible point of turn completion" (2002: 16). This also looks like a syntactic definition, but it obviously includes a much larger group of phenomena since nonmain-clause continuations of a TCU do not necessarily imply a structural link between the TCU and the increment. The increment may not be syntactically related to the host at all. Accordingly, Ford, Fox and Thompson distinguish between 'extensions' when the increments are "syntactically and semantically coherent" (16) with the preceding utterance, and 'free constituents' if there is no syntactic - but still, presumably, some semantic - coherence. Of these free constituents they analyse one type, i.e. unattached NPs, in more detail. Another example of 'free constituents' are the free-standing että-clauses of Finnish investigated by Seppänen and Laury in this volume. 'Extensions' (Schegloff's 'increments') are said to address problems of recipiency (lack of up-take), whereas unattached NPs can (also) "display a stance toward what has just been said" (2002: 26). As such, they perform a "new action, one of assessing and stance-taking toward a referent" (2002: 30). Note that Schegloff postulates that increments should not constitute a new action. If unattached NPs are increments but also actions, then this criterion is no longer applicable. In line with Ford, Fox and Thompson's argument, the criterion might be reformulated to say that increments do backward-oriented (retrospective) actions but never forward-oriented actions. Retrospective actions refer back to the action performed in the host utterance, and they are subsidiary to this action just as they are syntactically 'dependent' (again in a very loose sense of the word) on it.

Kim (this volume) takes yet another syntactic view on increments (a term he uses interchangeably with 'post-predicate elements'). In his Korean data, syntactically linked but non-projected expansions of a TCU are never linearly added as in the English data, but always occur after a canonical syntactic completion point. He gives a detailed account of the actions performed by these expansions, and once more it appears that, although syntactically 'integrated' in the host, they can do actions of their own, such as giving an account of the previous action (see his example 10). Again it turns out that increments can perform actions, but only retrospectively oriented, subsidiary ones which specify, comment on, mitigate ... previous actions.

Can we account for increments in terms of information structure? Luke \& Zhang (this volume) propose such a pragmatic definition: "If further talk is presented as an independent piece of new or significant information and forms a focus in its own right, we are more likely to be witnessing a case of turn extension. On the other hand, if further talk is presented as a piece of information which is already known (e.g. an old topic) or supplementary or relatively insignificant in information context (...) then we are more likely to have a case of TCU extension." (this volume). This sounds plausible, and is an interesting specification of what is meant by subsidiary actions, but at a closer look, it leads to problems. Some TCU expansions are clearly grammatically linked to their host but provide an independent piece of rhematic information and a semantic focus in their own right. One example, which I have discussed in more detail in Auer (1996; also cf. Uhmann 1997: 68), is the following:

\section{(1) CHINA 12}

H: der EIne: hh war ma verDROSChen worden vonner ganzen .h HORde: chinesischer kommilitonen.$h$ 
weil er (-) sich erdREIStet hatte: $h$ eine chiNEsin zum TEE einzulad $[\mathrm{en} .=(\uparrow) \mathrm{NACHmittags}$

S:

[NEI:N

H: one of them ((sc., the African students in China)) had been beaten up by a whole gang of Chinese fellow students because he (-) had dared to invite a Chinese woman for te $[\mathrm{a}=$ in the afternoon

S:

[no:::

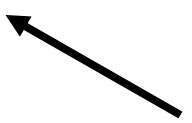

$\mathrm{H}$, the teller of the story, expands the TCU which contains the main line of her story (Chinese mob beats up a black person who has'dared to invite a Chinese woman for tea') by an adverb (nachmittags) which integrates in the syntactic pattern of the host (... eine Chinesin zum Tee einzuladen). But in pragmatic terms, this expansion clearly contains new and relevant information for the point the speaker wants to bring across: The invitation was 'in the afternoon', not in the evening, and therefore implied no violation of decency rules. The expansion is presented as having high informational value by prosody, particularly by its very high onset and the strong stress on the initial syllable.

My short review of some ways to approach 'increments' in syntactic and pragmatic terms (the latter partly referring to actions, partly to information structure) points to a number of problems or at least ambiguities in the ways this term is used:

(i) the role of syntax is unclear. While there is general agreement that increments occur after a point of syntactic closure (at which syntactic projections are no longer in play), there is no agreement as to whether they integrate into the structure of the host, and if so, how. The problem is in part due to the fact that the increments' relationship to the host is language dependent, a point made very convincingly by Couper-Kuhlen and Ono (this volume). Different languages have different options for expanding syntactic structures, and in addition, they make use of them to different degrees. These options seem to be linked in a non-trivial and yet-to-be-described way to the overall syntactic structure of each language. It will not get us very far to investigate the 'syntax of increments' without taking into account, for instance, whether the language is verb-final or verb-second, whether it has sentence-final particles, whether it is configurational or non-configurational, left- or right-branching, etc. For instance, as a V2-language, English does not mark the end of a syntactic construction; this makes it possible to add constituents to a sentence, an option which is more restricted in verb-final languages. On the other hand, strict verb-final languages have means to retrospectively rework parts of the already complete syntactic structure which seem to be less exploited in verb-second languages (see again Couper-Kuhlen/Ono, this volume).

(ii) it is not clear to what extent increments can be said to constitute actions of their own. Post-positioned accounts or stance expressions are actions, but in a different sense from the actions to which they are added. In order to come to a better understanding of increments and new TCUs, an understanding of dependent (subsidiary, retrospective) vs. main actions is necessary. 
(iii) the role of intonation has not been sufficiently integrated into research on increments.

(iv) finally, it is unclear how the syntactic and action dimensions correlate in increments. Intuitively, increments seem to map syntactic structure onto action structure: Turn extensions are new actions, TCU extensions are subsidiary/retrospective actions (see Couper-Kuhlen/Ono, this volume). It is obvious, however, that such a simple mapping of syntax on pragmatics or the other way round will not do. It is true that in many cases (which could be called prototypical), syntactic (formal) integration of the expansion into the host structure corresponds to the expansion's pragmatic dependence on the host. But there are many cases of turn expansion which are retrospectively oriented and do not start a new action, and equally there are at least some cases in which syntactic continuations (for instance, across speakers' turns) constitute new actions.

I suggest that the matter of unit expansion in conversational speech is a much larger issue than has been suggested in most work on increments so far, and that it should be approached in a more general way. In particular, unit expansion (including TCU expansion in the format of increments as discussed in the papers in this issue) is not a syntactic issue alone. There are ways to expand complete units in conversation in semantic, pragmatic, prosodic and syntactic ways, and sometimes even non-verbal (gestural, movement) patterns may be involved. These levels of semiotic structure are usually processed and interpreted by co-participants in a holistic way. For analysis, they can be separated, and the ways in which expansions can be done on each of them need to be explicated in technical terms. It may be easiest to start with a typology of syntactic expansions of a complete syntactic construction and analytically add further semiotic layers, such as prosody, to it, but in certain cases it may be more appropriate to start with non-verbal action or prosody. The distinction between TCU expansions and TCUinternal expansions will in the end turn out to be a gradual one, with many ambiguous or partial cases between clear dependence/integration into the host and clear restarting. Constellations of features on the various levels may coincide and support each other, but they may also diverge and make interpretation more ambiguous. In short, I suggest that the identification of TCU boundaries vs. TCU expansions is a highly interpretive issue which lay and professional analysts alike cannot reduce to a dichotomic distinction. Interpretations of expansions as actions are the result of partly complex and not always unequivocal processes of local inferencing which are based on linguistic cues such as the syntactic construction chosen, prosodic packaging, and other observable features such as speaker change.

I have suggested a partial typology of syntactic and prosodic unit expansions in previous papers $(1991,1992,1996)$ for German, and this typology has been developed further to provide a cross-linguistic perspective on expansions in papers by Vorreiter (2003) and Couper-Kuhlen/Ono (this volume). The ways in which syntactically complete constructions can be expanded will minimally include postponed elements which 'ought to' have been placed earlier, repairs on certain syntactic positions in the host, and continuations on various levels (phrase-level, sentence-level). They imply various types of operations on the host (such as syntagmatic retrogressive insertion, paradigmatic retrogressive replacement, and syntagmatic progressive continuation; see 
Auer 1992, 1996). However, I do not believe that a purely syntactic treatment of unit expansion (or, for that matter, 'incrementing') is satisfactory, although it may provide a useful starting point. It is true that syntactic expansions all use syntactic information in the host, and are therefore dependent on it. But 'dependency' on the host is a very general notion. It also applies to instances of what are often referred to as 'elliptical' utterances which do not always intuitively qualify as expansions. Also, there are many cases of unit continuation which do not qualify as expansions because their prosodic make-up is not that of an expansion.

In the remainder of this afterthought, I will discuss a small number of (German) examples to provide an idea of why a syntactic approach to incrementing is not sufficient, and how it might be integrated into a more comprehensive perspective. ${ }^{1}$

(2) Vere: $\quad<<$ all, $p>$ früher sind wir sonntags immer chinesisch ESsen gegangen. $>$ formerly have we sundays always chinese eating gone

$\longrightarrow \quad(-)$ mit der famIlie;> with the family

'On Sundays we always used to go out for Chinese food (-) with the family'

(2) is a case of straightforward syntactic unit expansion ('incrementing'). Mit der familie adds an adverbial phrase after the right sentence brace which defines the end of most German sentences, German being a V-last language. ${ }^{2}$ The expansion is set off by intonation and constitutes an intonational phrase of its own, i.e. syntax and prosody 'parse' the turn in the same way. Semantically and pragmatically, the expansion specifies the proposition 'On Sundays we always used to go out for Chinese food' by giving details about the 'we' - certainly a subordinated activity. Let us call this the prototypical expansion for the moment.

(3a) is already more difficult:

(3) Adr: hier wird ORdentlich gegessen heute.

a here is orderly eaten today

$\mathrm{b} \rightarrow$ NICHT geschAUfelt. not dug in

'We're going to eat properly today - no gobbling'

Syntactically, it is no different from (2) - an adverbial follows the right sentence brace but prosodically, the expansion is not marked. As I have argued in Auer (1996), prosody may camouflage or expose a syntactic expansion. While prosodic units and syntactic units are mapped on to each other in a one-to-one fashion in (2), the speaker in (3a) camouflages the syntactic expansion by producing it within the intonational phrase of

\footnotetext{
${ }^{1}$ All extracts are from a German reality TV show (Big Brother BB72, $1^{\text {st }}$ season ).

${ }^{2}$ In main clauses, it is the non-finite parts of the verb which are end-positioned.
} 
the host. It is not clear if we can speak of the heute as doing an action (if only subsidiary) of its own.

Also note that from a purely syntactic point of view, it is not obvious that instances such as (3a) should be considered expansions at all. It could be argued that they are constructions specific to spoken German, i.e. that the 'expansion' looks like an expansion from the normative point of view of written language only (see CouperKuhlen/Ono, this volume). It is not easy to decide between these two alternatives, but the mere fact that two syntactic interpretations are possible already shows that prosodically integrated post-verbal (post-field) adverbials are non-prototypical expansions.

(3b) is also difficult to analyse. Many linguists would speak of an elliptical utterance which 'rides' on the syntactic structure of the host:

\begin{tabular}{|l|l|l|l|}
\hline hier & wird & ordentlich & gegessen \\
\hline (hier) & (wird) & nicht & geschaufelt \\
\hline ADVB & $\mathrm{V}_{\text {fin }}$ & DVB & $\mathrm{V}_{\text {part }}$ \\
\hline
\end{tabular}

Nicht geschaufelt paradigmatically replaces ordentlich gegessen in the host. Therefore, the second utterance depends structurally on the first and qualifies as a syntactic expansion. Prosody supports a segmentation into two syntactic segments. But what about the semantics and pragmatics of the expansion? The negation builds up a contrast with the preceding utterance, and the reference to 'gobbling' provides the most central ('rhematic') information of the turn as a whole. It does not seem the case that the expansion modifies or elaborates the host; rather it is essential in providing the message and 'performing' the action of calling the table-mates to order (if somewhat ironically). Again, the expansion is atypical in that it displays the characteristic syntactic and prosodic features of expansions, but not the semantic/pragmatic ones.

The same argument applies to the next example, in an even stronger version:

(4) (talk about Chinese restaurants)

Jrg: $\quad<<\mathrm{f}>$ ja: wat MEINSTE wat de da ISST für den preis; $>$

well what think-you what you there eat for the price

(--) streunende HUNde. und KATzen.

stray dogs. and cats

'what do you think you eat there for that price - stray cats and dogs'

The speaker produces a question-answer sequence within his turn. The first unit contains the question word wat (std.G. was 'what') which needs a syntactically fitted response in the same case as the question word. This is provided in the second unit, as the coordinated noun phrase streunende Hunde und Katzen (in the accusative case). Answers to wh-questions therefore syntactically depend on their 'hosts' (the question). However, we would not consider 'stray dogs and cats' an expansion in the prototypical sense: The answer is the main information, surely an action of its own. (Note that both 
units contain candidates for unit expansions themselves: Wat MEINSTE wat de da ISST is a syntactically complete construct which is expanded by the prosodically integrated prepositional phrase für den preis; streunende HUNde equally qualifies as a syntactically complete construct and is expanded by the coordinated noun phrase und KATzen, which, however, is produced as an intonation contour of its own.)

While in the examples discussed so far either the pragmatic or the prosodic prototypical features of expansions were lacking, the next example displays prototypical prosodic and semantic features, but not the expected syntactic ones:

(5) (Andrea is preparing a Chinese meal)

Adr: $\quad$ du kannst wenn de magst $\mathrm{n}$ bisschen den saLAT putzen;

you can if you like a little the salad clean

.h und MÖRchen brauch ich klEIn geschnitten;

and carrots need I small cut

'if you like you could clean the salad a bit, and I need carrots, cut in small pieces'

The relevant expansion is klein geschnitten, attached to the host mörchen brauch ich. In traditional terms, it would be analysed as an apposition, since the perfect participle geschnitten does not agree in number with the object mörchen to which it is attached (the inflected form would be geschnittene). It is not clear which kind of syntactic relationship links the two, even more so since a 'non-expansive' version such as

und mörchen klein geschnitten brauch ich

is only marginally acceptable in modern German, and

und klein geschnitten mörchen brauch ich

is not at all. (The syntactially integrated, non-expanding version of the sentence would be

und klein geschnittene mörchen brauch ich

with the inflected adjective preceding its head.) The 'appositional' structure seems to be a special syntactic construction for unit expansion.

Finally, a somewhat more complex case may show how unit expansion is not something exceptional (dealing, for instance, with turn-taking problems such as lack of uptake) but a fundamental and pervasive technique of the sequential structure of conversational talk.

(6) (The Big Brother container inhabitants talk about their desire to leave the container; Verena argues that everybody has moments where s/he wishes to leave, while Sabrina believes that their co-inhabitant Jürgen never feels that way.) 
Vere: isch denk der jürgen hat AUCH momente wo er; .h

I think the Jürgen has also moments where he

Sbr: $\quad<<$ with force $>$ nä $>$

no

Vere: $\quad$ nach HAUse will;

back home wants

meinste NICH?

think-you not

Sbr: (--)wo er SEHNsucht [hat.= where he longing has

Vere: $\quad[j a$

yeah

Sbr: =aber jürgen=der JÜRgen würde nich GEHN.=

but jürgen the Jürgen would not go

$=$ außer seine sch seine tochter wär $\mathrm{h}(0.5)$ am KRANkenbett. unless his sis his daughter was in-the hospital

(--) oder was.

or something

sonst würd der (jürgen)(.) nich GEHN.

otherwise would the (jürgen) not go

NIEmals. $=$

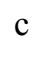

never

$=\mathrm{JOHN}$ ja.

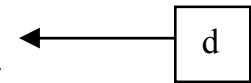

John yes

(--)JOHN jA.

John yes

hat=er ja selbst geSACHT.

has he PART himself said

alex und john JA.

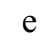

Alex and John yes

aber (.) jÜRgen? (.) NICHT.

but Jürgen not

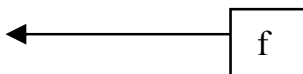

Vere: I think Jürgen also has moments where he; .h

Sbr.: no.

Vere: wants to go home.

don't you think so?

Sbr.: (--) where he is homesick.

but Jürgen wouldn't go.

unless his sis daughter was in hospital

or something 
he wouldn't go.

never.

John yes.

John yes.

he said it himself.

Alex and John yes

but Jürgen? no.

There is a continuous reworking of syntactic structures previously introduced by the same or another participant in this extract. Only some of these reworkings are marked by arrows. (6a) is a paradigmatic substitution in the previous presentational relative clause construction:

\begin{tabular}{|c|c|}
\hline der Jürgen hat auch Momente, & wo er nach Hause will \\
\hline (der Jürgen hat auch Momente,) & Sehnsucht hat \\
\hline main clause & relative clause \\
\hline
\end{tabular}

It is done by two different speakers, and by rephrasing Verena's statement Sabrina slightly criticises and corrects her description of Jürgen's state of mind. On the other hand, this action does not seem to be backward oriented in sequential terms but prepares the counter-argument that Jürgen would never leave the container which follows in the next TCU. (6b) is a sentence-level continuation of aber der jürgen würde nich gehen. which would not count as an increment in Ford/Fox \& Thompson's terms, since it is a main clause. On the other hand, it clearly performs a semantic operation of restricting the validity of her prior statement which seems typical for expansions.

(6c) is the result of a retrospective, paradigmatic operation on the host, replacing the simple negator nicht by the more emphatic temporal 'never' niemals:

\begin{tabular}{|l|l|l|}
\multicolumn{1}{l|}{} & & \\
John würd & nicht & gehen \\
John würd & niemals & gehen \\
\hline
\end{tabular}

(6d) - John ja - is an interesting case of 'ellipsis'. The host is

der [Jürgen] würde nich gehn.

From this construction, the 'expansion' takes the subject position and copies it. It is filled by the noun phrase John which now occupies the syntactic slot provided by der or Jürgen in the host utterance. The predicate of the host is copied verbatim but changes polarity through the particle ja, which turns the negative predication 'would not go' into a positive one 'would go'. Although syntactically dependent on the host, and 
prosodically a self-contained unit, John ja is pragmatically not a prototypical expansion. Rather, it contains rhematic information and is a 'new step' in the argument Sabrina is about to construct. (6e) reworks the 'subject phrase' in John ja by adding Alex to it, while (6f) again switches polarity - now from positive to negative - by the particle nicht:

\begin{tabular}{|l|l|}
\hline der [Jürgen] & würd nicht gehen \\
\hline John & ja \\
\hline John und Alex & ja \\
\hline Jürgen & nicht \\
\hline SUBJECT & PREDICATE \\
\hline & \\
&
\end{tabular}

The point is that speakers continually rework and elaborate their own or other speakers' utterances by making use of already existing syntactic structures. They thereby produce 'expansions' of complete syntactic units. These expansions may involve simple continuations but also radical reorganisations. Prosody may camouflage or integrate them. Their information status may be rhematic or thematic, their semantics cohesive or not, and they may constitute new actions or subsidiary ones. One of the ways in which the various levels of organisation of interaction can conspire to achieve a multi-modally bounded construction is 'increments'; however, there are many other such methods equally worthy of a detailed interactional analysis.

In sum, I have tried to make two arguments in this paper. In the first part I have argued that an approach to unit expansions as 'increments' in the sense of Schegloff 1996 , i.e. as linearly added, syntactically dependent segments which do not perform an action in themselves (at best a subsidiary one), and which are prosodically exposed, is too narrowly focused on English. While the structure of English makes it particularly suited for this kind of expansion, this notion of incrementing fails to capture what goes on in a wider variety of languages. In the second part of the paper, I have argued that even a more sophisticated and typologically more satisfactory approach to unit expansion runs into problems if it remains on the syntactic plane alone. A full typology will have to take into account, not only prosody and semantics, but also action structure and pragmatics at large. It may also be in need of a non-verbal component.

\section{References}

Auer, Peter (1991) Vom Ende deutscher Sätze. Zeitschrift für Germanistische Linguistik 19.2: 139-157.

Auer, Peter (1992) The neverending sentence: Rightward expansion in spoken language. In M. Kontra, and T. Váradi (eds.), Studies in Spoken Languages: English, German, Finno-Ugric. Budapest: Linguistic Institute at the Hungarian Academy of Sciences, pp 41-59.

Auer, Peter (1996) On the prosody and syntax of turn-continuations. In E. Couper-Kuhlen and M. Selting (eds.), Prosody in Conversation. Cambridge: Cambridge University Press, pp 51-100. 


\section{Peter Auer}

Ford, Cecilia E., Barbara A. Fox, and Sandra A. Thompson (2002) Constituency and the grammar of turn increments. In eaedem (eds), The Language of Turn and Sequence. Oxford/New York: Oxford University Press, pp 14-38.

Schegloff, Emanuel (1996) Turn organization: One intersection of grammar and interaction. In: E. Ochs, E.A. Schegloff, and S.A. Thompson (eds.), Interaction and Grammar. Cambridge: Cambridge University Press, pp 52-133.

Uhmann, Susanne (1997) Grammatische Regeln und Konversationelle Strategien. Tübingen: Niemeyer.

Vorreiter, Susanne (2003) Turn continuations. Towards a cross-linguistic classification. INLIST 39 (http://www.rz.uni-potsdam.de/u/inlist) 